\title{
A interculturalidade como orientação metodológica e de análises na comunicação organizacional
}

Interculturalism as methodological guidance and analyses in organizational communication

La interculturalidad como orientación metodológica y de análisis en la comunicación organizacional

(9) Viviane Fushimi Velloso

- Doutora em Ciências da Comunicação pela Escola de Comunicações e Artes da Universidade de São Paulo (ECA-USP)

- Mestre em Ciências da Comunicação pela ECA-USP

- Graduada em Jornalismo pelo Centro Universitário das Faculdades Integradas Alcântara Machado (UniFiam-Faam)

- Professora assistente II da Universidade de Taubaté (Unitau)

- E-mail: vivianefv@gmail.com

(9) Mitsuru Higuchi Yanaze

- Doutor em Ciências da Comunicação pela Escola de Comunicações e Artes da Universidade de São Paulo (ECA-USP)

- Mestre em Business Administration pela Michigan State University

- Graduado em Publicidade e Propaganda pela ECA-USP

- Especialista em Administração de Empresas pela Fundação Getúlio Vargas (FGV Professor titular do Departamento de Relações Públicas, Propaganda e Turismo da ECA-USP

- Coordenador do Centro de Estudos de Avaliação e Mensuração em Comunicação e Marketing (Ceacom) da ECA-USP

- Consultor de empresas e palestrante

- E-mail:mitsuruyanaze@uol.com.br 


\section{Resumo}

A complexidade do ambiente organizacional aumenta devido às transformações econômicas, sociais e culturais. Isso é impulsionado pelos avanços da globalização e da internacionalização, além da evolução tecnológica. Nesse cenário, a interculturalidade evidencia a necessidade de aprimorar os métodos da comunicação organizacional, visando imprimir efetividade em suas estratégias e práticas. Neste artigo, é apresentada uma proposta metodológica, embasada no estudo da interface comunicação e tecnologias da informação, pautada em observação, pesquisas e análises, visando à "comunicação excelente" por meio das "expectativas compartilhadas".

PALAVCRAS-CHAVE: GESTÃO E PLANEJAMENTO • COMUNICAÇÃO ORGANIZACIONAL • TECNOLOGIAS DA INFORMAÇÃO E COMUNICAÇÃO • INTERCULTURALIDADE.

\section{Abstract}

The complexity of the organizational environment increases due to economic, social and cultural transformations. This is driven by the advances of globalization and internationalization, as well as by technological developments. In this scenario, the interculturalism reveals the need to enhance the organizational communication methods, aiming at enhancing the effectiveness of its strategies and practices. In this article one presents a methodological proposal, based on a study of the interface between communication and information technologies, based on observation, research and analyses, aiming at the "excellent communication" by means of the "shared expectations".

KEYWORDS: MANAGEMENT AND PLANNING • ORGANIZATIONAL COMMUNICATION • INFORMATION TECHNOLOGY AND COMMUNICATION • INTERCULTURALISM.

\section{Resumo}

La complejidad del ambiente organizacional aumenta debido a las transformaciones económicas, sociales y culturales. Eso es impulsado por los avances de la globalización y de la internacionalización, además de la evolución tecnológica. En ese escenario, la interculturalidad enfatiza la necesidad de mejorar los métodos de la comunicación organizacional con el fin de imprimir efectividad en sus estrategias y prácticas. En este artículo se presenta una propuesta metodológica fundada en el estudio sobre la interface de comunicación y tecnologías de la información, pautada en la observación, la investigación y el análisis, con el objetivo de una "comunicación excelente" por medio de las "expectativas compartidas". 
cenário de transformações e a popularização das tecnologias de informação e comunicação vêm delineando uma "sociedade em rede". Essa sociedade é alicerçada pelo "informacionalismo" (Castells, 2008). Em suporte tecnológico, 0 real e o virtual tornaram-se complementares. Cria-se um novo espaço, chamado por Castells (2008) de "virtualidade", com o poder de estabelecer relacionamentos de diversos tipos, pela diversidade de informações, pela multiplicidade de fontes e manifestações complexas de opinião.

O cenário atual de mercados globalizados torna imperativa a internacionalização das empresas e a adequação das estruturas de gerenciamento e de produção, imersos em um sistema social global (Kunsch, 2003, p. 125-139). Contudo, nota-se a crescente dificuldade em atender às necessidades dos modelos adotados, que sofrem alterações por motivo de interferências culturais, políticas e econômicas locais.

Diante dessecenário, este artigo demonstra a aplicação de uma metodologia deanálise de interação entre aárea de comunicação organizacional e a área de tecnologia da informação. 0 intuito é contribuir para a compreensão da diversidade funcional e cultural dessas duas áreas e as possibilidades de construção de cenários compartilhados de interesse nas organizações, com referência nos princípios da comunicação excelente (Grunig, 1992).

\section{O CONTEXTO DA COMUNICAÇÃO E A TECNOLOGIA DA INFORMAÇÃO NAS ORGANIZAÇÕES}

Com o surgimento de uma "nova economia", delineada a partir do "último quartel do século XX", como "informacional, global e em rede" (Castells, 2008, p. 119), no contexto da internacionalização e globalização, revelam-se inúmeras modificações no sistema de gestão e produção.

A tecnologia da informação é vista como fonte de criação de novas estratégias de negócio, de novas estruturas organizacionais e de novas formas de relacionamentos entre empresas e entre empresas e seus consumidores (Laurindo, 2011, p. 2).

Considerando as trocas pautadas pela comunicação digital e o contexto de complexidade das relações humanas, os estudos de comunicação nas organizações necessitam "compreender os diferentes componentes (subsistemas) que integram uma organização" (Rebeil-Corella, 2009, p. 95), para obter uma configuração mais apropriada ao espaço-tempo organizacional.

Nesse sentido, verifica-se que, em tempos de internacionalização das empresas, as questões se tornam mais complexas, uma vez que a particularidade de cada setor organizacional, com seus processos e sujeitos, traz à cena a interculturalidade, destacada por diversos autores (lanni, 2004 e 2005; Canclini, 2003; Ferrari, 2012). Relações, hábitos e costumes são confrontados no ambiente organizacional e para que a comunicação seja efetiva, necessita-se da interação entre as partes envolvidas nos processos organizacionais.

Na perspectiva de Grunig (2009, p. 25-26), a "teoria de gestão estratégica das relações públicas contém elementos do modernismo e do pós-modernismo", ou seja, por um lado, "ajuda a organização a controlar seu ambiente" e, por outro lado, "leva à esfera do processo decisório os problemas dos públicos como problemas administrativos". As trocas comunicativas efetivam-se por diálogos, processos de negociação e colaboração. 
Para David M. Dozier, Larissa Grunig e James(1995), a comunicação "excelente" éestruturada em três esferas da excelência. A primeira camada é o "núcleo do conhecimento", a segunda camada, das "expectativas compartilhadas", e a terceira, da "cultura participativa".

Verifica-se que, na conformação da "excelência", o "núcleo do conhecimento" está diretamente ligado aos princípios organizacionais, determinantes para o planejamento e direcionamento administrativo. Da mesma forma, o "núcleo das expectativas compartilhadas" preza pelas interações entre os níveis e departamentos administrativos e os públicos e stakeholders organizacionais.

As organizações com culturas predominantemente participativas infundem em seus funcionários valores compartilhados, fazendo com que eles se unam em equipe para alcançar uma missão comum. Abertas a ideias de fora, essas organizações são a favor da inovação e da adaptação ao invés da tradição e dominação (Dozier; Grunig, L.; Grunig, J., 1995, p. 17).

Por isso, o destaque ao preparo dos profissionais de comunicação para análise dos ambientes internos e externos da organização. Eles devem mapear os públicos de interesse, planejar e desenvolver políticas de relacionamento e, por fim, monitorar, mensurar e avaliar os relacionamentos entre a organização e esses públicos.

\section{UMA METODOLOGIA PARA AS EXPECTATIVAS COMPARTILHADAS ORGANIZACIONAIS}

A partir da necessidade de aprimorar as ações da comunicação administrativa, que "trata das estratégias e meios de comunicação das atividades de gestão, ou seja, do planejamento, da organização, da coordenação e do controle" (Yanaze, 2011, p. 452), buscou-se desenvolver uma metodologia de análise que oferecesse elementos para o desenvolvimento estratégico e tático diante de cenários de expectativas e necessidades de áreas organizacionais.

Há necessidade, pois, de um meio termo entre a subjetividade e a objetividade, a fim de possibilitar alcançar a eficiência e a eficácia da metodologia traçada, pautada pelo cenário complexo organizacional. Dessa forma, o estudo sobre a interação entre a área da comunicação e a da tecnologia da informação (TI), objeto da tese de doutorado de Viviane Fushimi Velloso (2014), buscou verificar as necessidades e expectativas da interface da comunicação com a TI e estruturou-se pela observação, pesquisa e análise.

Para tanto as buscou-se inicialmente um constructo para os aspectos da "excelência", de forma que o "núcleo do conhecimento", "expectativas compartilhadas" pudessem embasar a metodologia de coleta e análise dos cenários de tecnologia da informação e comunicação, considerando uma estruturação voltada para uma "cultura participativa" (Dozier; Grunig, L.; Grunig, J., 1995).

Sendo assim, elaborou-se uma sistemática observacional do ambiente de interação com a comunicação.

Um dos métodos mais utilizados nas ciências sociais (...), considerado como o mais primitivo, (...) pode ser tido como um dos mais modernos, visto ser o que possibilita o mais elevado grau de precisão nas ciências sociais (Gil, 2002, p. 35).

Dessa forma, a pesquisa exploratória organizou-se a partir de conversas, entrevistas, observação grupal, com o objetivo de identificar as principais características da área de Tl: comportamento dos profissionais, discursos comuns, jargões e comportamento relacional. 
Adotou-se a "observação direta intensiva", que "utiliza os sentidos na obtenção de determinados aspectos da realidade [e] não consiste apenas em ver e ouvir, mas também em examinar fatos e ou fenômenos que se deseja estudar" (Lakatos; Maroni, 2001, p. 107). Por outro lado, na área da comunicação, com a mesma técnica, buscou-se identificar também as principais observações dos profissionais da área, sobre a área de TI e seus profissionais.

Essa fase ofereceu subsídio para a elaboração da pesquisa quantitativa, para as duas áreas - comunicação e TI. Sendo assim, para o incremento da pesquisa descritiva e construção de uma base de dados sobre os profissionais das duas áreas de interação, TI e comunicação, foi proposto como instrumento de coleta de dados um questionário estruturado (Samara; Barros; 2007, p. 120), com perguntas fechadas e apenas uma aberta, destinada a identificar opiniões pessoais sobre o assunto e as expectativas e necessidade dos profissionais sobre uma interface entre as áreas.

Evidencia-se que as análises das informações da pesquisa exploratória ofereceram um caráter qualitativo às respostas, pela assertividade dos enunciados, que também estimularam a participação do entrevistado na questão aberta, por sua objetividade e clareza.

0 objetivo desse instrumento foi traçar o perfil dos profissionais de ambas as áreas, seus conhecimentos sobre suas atividades e seu papel na organização, suas percepções sobre a área de interface e as dificuldades de interação. Isso possibilitou delinear características básicas das áreas investigadas, propiciando iniciar um "núcleo de conhecimento" sobre cada uma delas, bem como traçar o campo das "expectativas" desses profissionais sobre a interação.

No processo de elaboração das questões, foi aplicado um pré-teste. Contudo, no caso específico da tese de Velloso (2014, p. 20), optou-se pela utilização da plataforma eletrônica denominada Surveymonkey, considerando o perfil dos profissionais envolvidos na pesquisa, que se relacionam em seu ambiente de trabalho com computadores, internet e redes de relacionamento.

A experiência e as dificuldades com a obtenção de respostas na aplicação do pré-teste sugeriam que o método mais adequado para a realização da pesquisa fosse a "bola de neve" (snowball). Nesse método, os contatos iniciais podiam convidar outros respondentes que considerassem interessantes e, assim, o questionário foi aplicado em uma amostra não concentrada. $\mathrm{A}$ técnica, utilizada na antropologia, foi proposta por H. Russell Bernard (1996).

Depois de traçar o cálculo amostral (Velloso, 2014, p. 21), estabeleceu-se a distribuição dos questionários aos grupos de profissionais de TI e de comunicação. Optou-se por aqueles que apresentavam um bom "grau de centralidade no cluster" , disseminadores dos questionários. A lista inicial contou com duzentos da área de TI e cem da comunicação. Cabe ressaltar que foram criados, em Tl e em Comunicação, dois coletores na rede de relacionamento Linkedin para cada área.

Acredita-se que o método escolhido foi eficiente para a pesquisa, devido à estratégia criada para o encaminhamento e o controle da aplicação dos questionários. Isso permitiu, por saturação (Velloso, 2014, p. 22) encerrar com cem questionários respondidos por profissionais de TI e 151 questionários respondidos por profissionais de comunicação. 
$O$ período da coleta estendeu-se pelos meses de março, abril, maio e junho de 2013. Um destaque foi a participação espontânea dos profissionais de comunicação, na questão aberta, que somaram cinquenta respondentes, sendo que em TI a questão espontânea somou quinze respondentes.

Diante desse fato, a preocupação na construção de um "núcleo de conhecimentos" sólido levou à elaboração de uma pesquisa qualitativa com técnica de entrevista em profundidade para "recolher respostas subjetivas a partir da experiência de uma fonte" (Duarte, 2010, p. 63), com gestores de TI.

Por se tratar de uma pesquisa não probabilística, por conveniência, com alto valor de subjetividade do entrevistado, optou-se por não criar generalizações ou provar algo com as respostas, mas sim, buscar indicativos para a compreensão do fenômeno pesquisado, a partir de 15h de gravação (Velloso, 2014, p. 23).

Finalizado o processo de coleta de dados, iniciou-se o processo de seleção dos dados e a construção dos cenários de expectativas e necessidades de cada área, baseada na pesquisa exploratória, bibliográfica, descritiva-quantitativa e qualitativa - realizadas (Velloso, 2014, p. 118-159). Dessa forma, optou-se pelo cruzamento dos instrumentos de análises swot e GUT. Voltada ao planejamento estratégico, a análise swot - termo formado pelas iniciais das palavras strengths, weakenesses, opportunities and threats - foi criada por Kenneth Andrews e Roland Christensen, professores da Harvard Business School. Define-se como "modelo que compreende uma análise interna com o objetivo de levantar os pontos fortes e fracos da empresa, e uma análise do ambiente externo (...) para se apurar as oportunidades e ameaças (Yanaze, 2011, p. 300).

O Quadro 1 apresenta a base da matriz swote indica as possibilidades esperadas nos cruzamentos dos fatores identificados.

Quadro 1- Matriz swot.

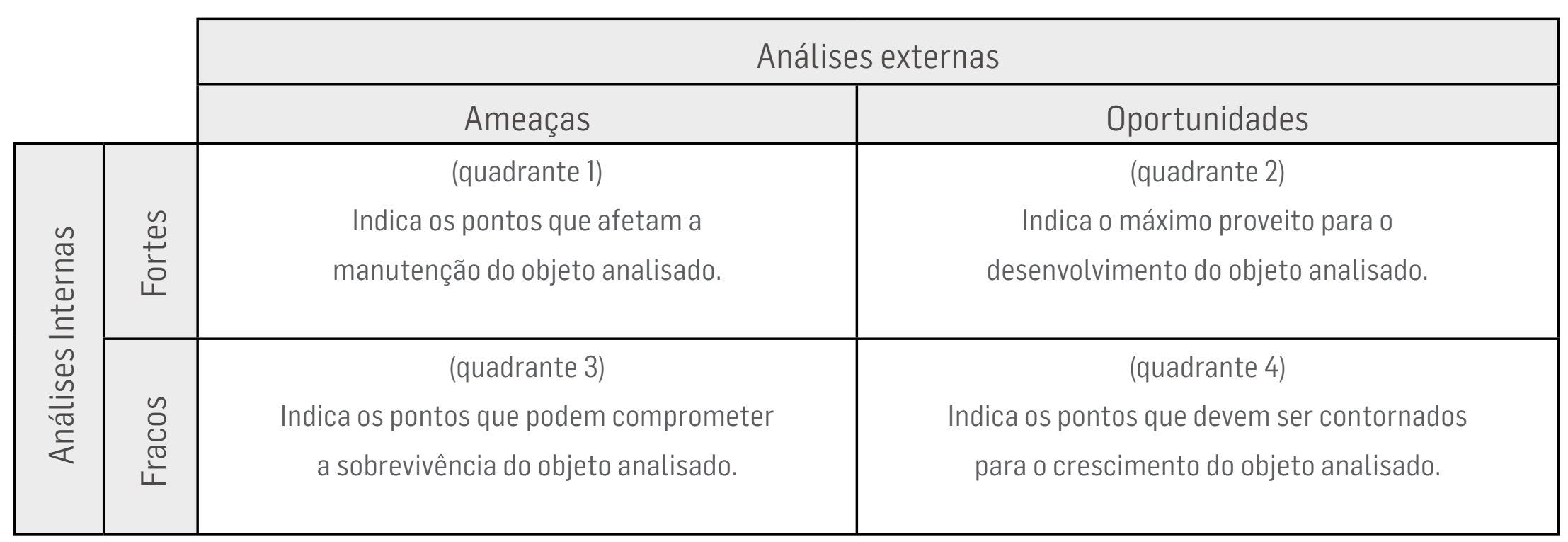

Fonte: Adaptada de Yanaze, 2011.

Essa matrizpermite o cruzamento entre os fatoresinternos externosque podemapontar umcenáriofavorávelàimplementação de ações estratégicas de uma organização. Também pode facilitar a identificação dos pontos mais relevantes e significativos para se iniciar uma intervenção. Da mesma forma, indica os pontos que podem comprometer ou prejudicar os processos.

Para tanto, identificaram-se os pontos em comum e aqueles específicos que compunham a estrutura básica de cada área e que obtiveram destaque em cada fase de coleta. Os pontos enfatizados pelas teorias foram confrontados com os dados 
apurados pela pesquisa de campo e estruturou-se o ambiente interno e externo de cada área - neste último, as interferências do ambiente governamental e organizacional.

Porém, diante do cenário que se delineava, a necessidade de priorização no cruzamento levou à escolha da metodologia GUT. Segundo Djalma P. Rebouças de Oliveira (2002, p. 140-141), a identificação dos pontos da análise swot não deve ser feita de maneira despretensiosa e a metodologia de Kepner e Tregoe (1981) deve ser aplicada para a "fixação de prioridade de fatores". Sendo assim, a metodologia GUT - iniciais de gravidade, urgência e tendência - possibilita indicar a gravidade, a urgência e a tendência dos pontos encontrados.

Para tanto, o Quadro 2 apresenta a escala criada para definição dos parâmetros.

\section{Quadro 2-Referência de análise da metodologia GUT}

\begin{tabular}{|c|c|c|c|}
\hline & $\begin{array}{c}\text { Gravidade } \\
\text { (Significância do dano) }\end{array}$ & $\begin{array}{c}\text { Urgência } \\
\text { (Período de tempo } \\
\text { para a ação) }\end{array}$ & $\begin{array}{c}\text { Tendência } \\
\text { (Desenvolvimento do problema) }\end{array}$ \\
\hline 1. & Dano mínimo & 1. Longuíssimo prazo & 1. Desaparece \\
\hline 2. & Dano Leve & 2. Longo prazo & 2. Reduz rapidamente \\
\hline 3. & Dano médio & 3. Médio Prazo & 3. Permanecer \\
\hline 4. & Grave & 4. Curto prazo & 4. Aumenta \\
\hline 5. & Gravíssimo & 5. Imediatamente & 5. iora muito \\
\hline
\end{tabular}

Fonte: Baseado em Meirelles, 2001.

Observa-se no Quadro 3 a escala pontuada do cruzamento, que determina o posicionamento dos fatores da matriz swot na relação com a matriz GUT.

Quadro 3 - Escala de pontuação no cruzamento da matriz GUT

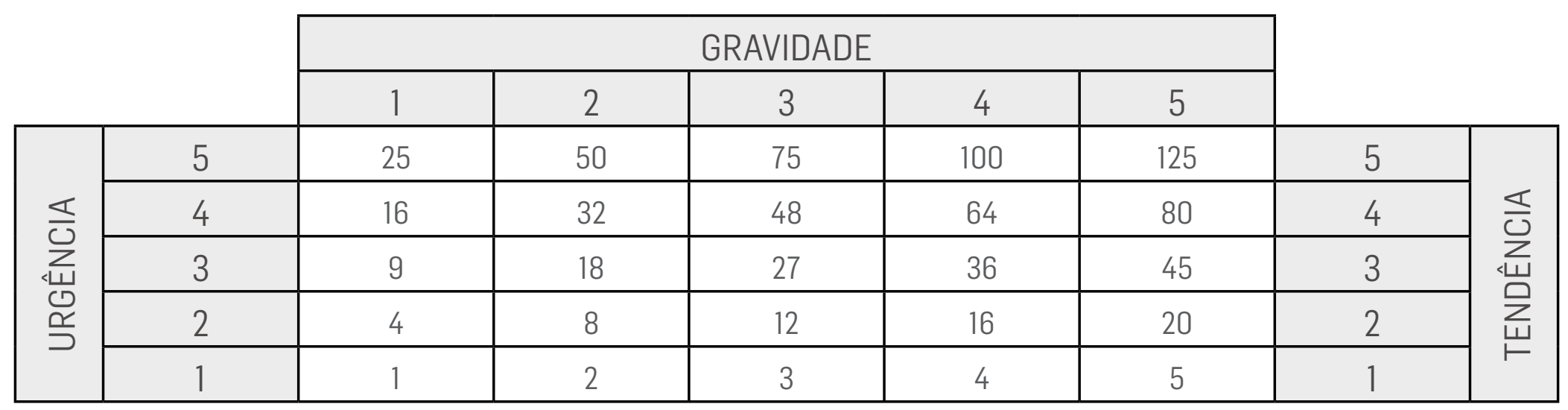

Fonte: Velloso, 2014.

Dessa forma, elaborou-se uma análise que permitiu a identificação de cenário de ambas às áreas e posteriormente ofereceu suporte à elaboração das proposições finais da tese de doutorado (Velloso, 2014). 


\section{RESULTADOS E ANÁLISES}

Os dados quantitativos propiciaram leituras gráficas eficientes sobre o perfil profissional de cada área, bem como identificar a percepção dos profissionais sobre sua área e a área de interface (Velloso, 2014, p. 118-136; 145-157).

A análise do conteúdo das respostas provenientes da questão aberta possibilitou a classificação das opiniões sobre a interface por parte dos profissionais das duas áreas, bem como a identificação de necessidades e expectativas que não haviam sido apontadas na pesquisa exploratória e que foram estimuladas pelas questões fechadas. Assim a apropriação das opiniões classificadas na pesquisa em questão foi dividida em depoimentos sobre a interface: positivos, negativos, neutros e dicotômicos - aqueles que demonstravam dubiedade de sentidos (Velloso, 2014, p. 136-137; 157-159).

A pesquisa bibliográfica, que balizou a revisão bibliográfica em TI(Velloso, 2014, p. 83-107), ea entrevista em profundidade permitiram uma visão crítica sobre a área de TI (Velloso, 2014, p. 137-144) e identificaram conflitos e falhas comunicacionais nos processos de TI.

Definido o status de cada um dos fatores identificados no cruzamento, para definição da pontuação foram somados os números individuais e divididos por dois, configurando o número total de fatores no cruzamento. Ao encontrar um número correspondente à matriz GUT referente ao cruzamento dos fatores analisados da matriz swot, é possível apontar as prioridades desse contexto que necessitam de tratamento. 0 Quadro 4 destaca o cenário de TI e os pontos e destaque identificam os conflitos organizacionais prioritários, em rosa, e os segundos mais altos, em azul.

\section{Quadro 4 - Matriz swote matriz GUT na identificação de prioridades em TI.}

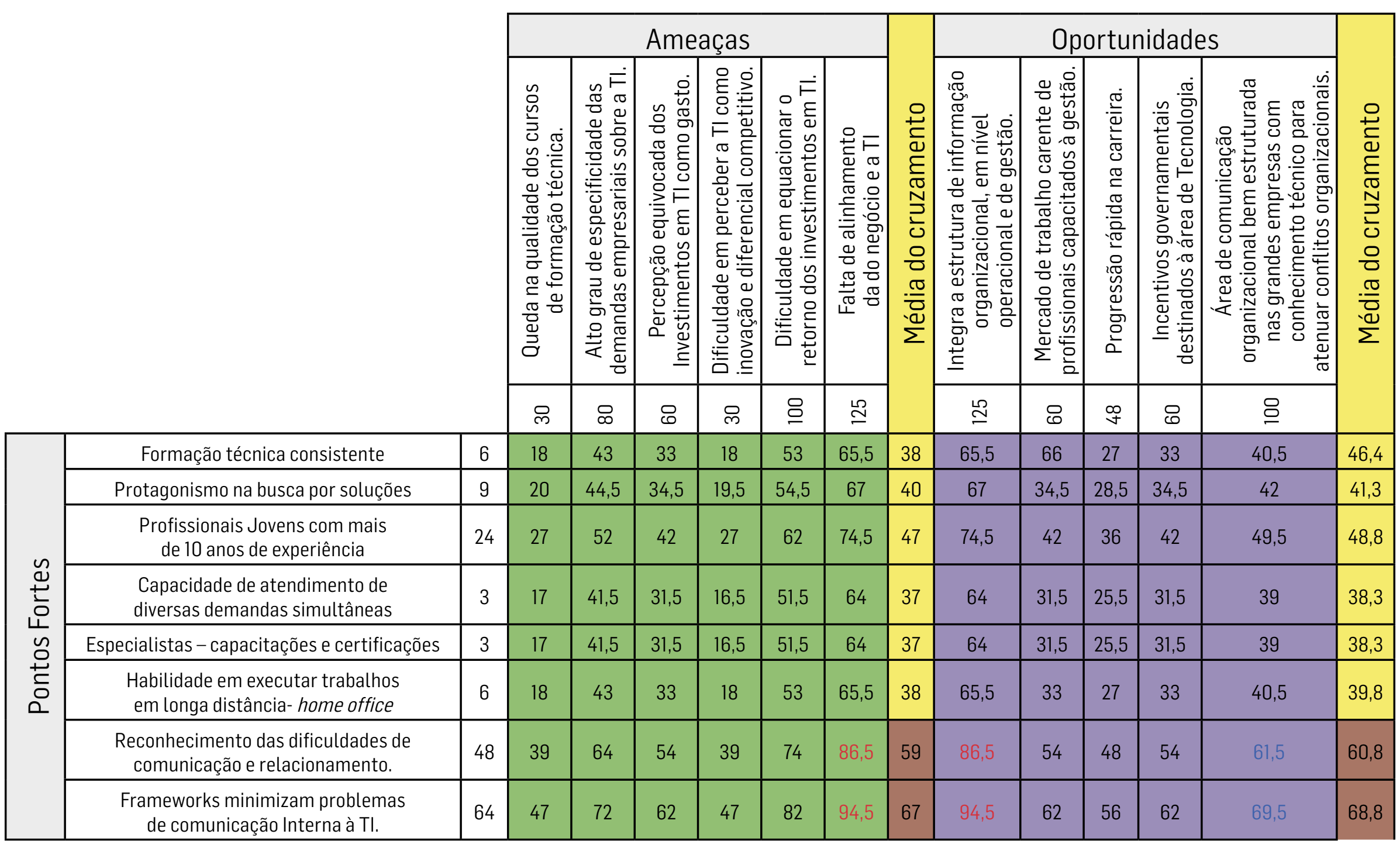




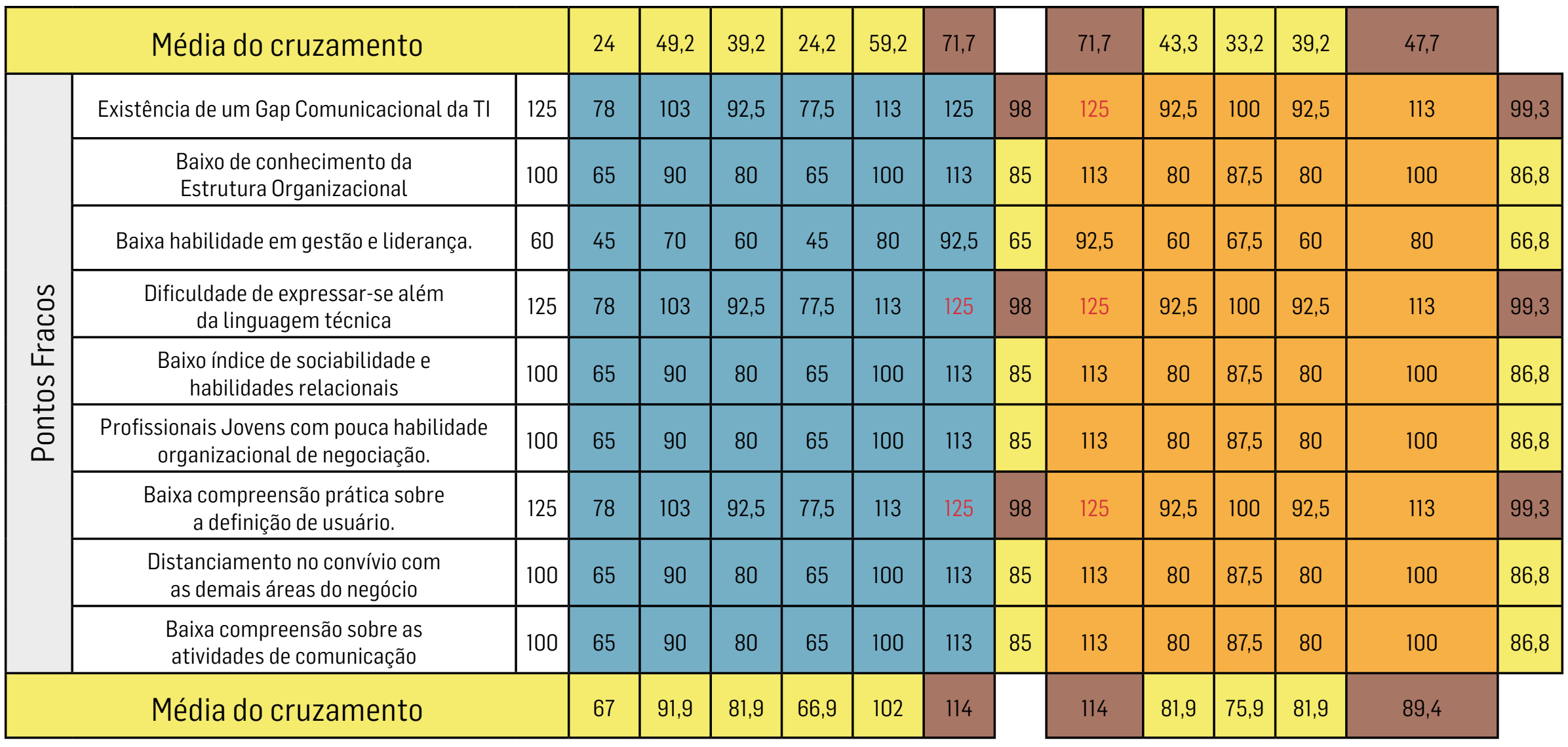

Fonte: Velloso, 2014.

No quadrante 1 (verde), o quesito alinhamento da TI ao negócio representa a principal ameaça; contudo, o reconhecimento dos profissionais de TI quanto às dificuldades que se apresentam em comunicação e relacionamento é um ponto forte significativo.

0 quadrante 2 (lilás) diz respeito ao emprego dos frameworks, que minimizam os problemas de comunicação interna à TI, 0 que evidencia o máximo proveito obtido para a organização no que se refere à integração, por TI, da estrutura de informação organizacional em nível operacional e de gestão. Em segundo lugar se destaca o fato de as grandes empresas apresentarem uma área de comunicação bem estruturada e com conhecimento técnico voltado para atenuar conflitos organizacionais.

Os itens com prioridade mais alta são aqueles situados no quadrante 3 (azul), aqueles que comprometem a organização no que se refere ao alinhamento da TI com o negócio. Fica evidente que a existência do gap comunicacional de Tl e a dificuldade de se expressar, além da linguagem técnica e da baixa compreensão prática sobre a definição de usuário, são os itens que necessitam de prioridade no tratamento.

No quadrante 4 (laranja), verifica-se que o fato de a TI integrar a estrutura de informação organizacional, nos níveis operacionais e de gestão, permite relação mais positiva para o contorno das deficiências identificadas. Ao considerar a comunicação como uma oportunidade, verifica-se, nos quadrantes 2 (lilás) e 4 (laranja), a possibilidade alta de impacto, uma vez que se destaca como o segundo número mais alto, colorido em azul.

O Quadro 5 destaca o cenário de comunicação e os pontos de destaque identificam os conflitos organizacionais prioritários. 
Quadro 5 - Matriz swote matriz GUT na identificação de prioridades em comunicação

\begin{tabular}{|c|c|c|c|c|c|c|c|c|c|c|c|c|c|c|}
\hline & & & & & & & & & & & & & & \\
\hline & & & \multicolumn{5}{|c|}{ Ameaças } & \multicolumn{6}{|c|}{ Oportunidades } & \multirow{3}{*}{ 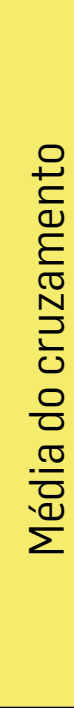 } \\
\hline & & & 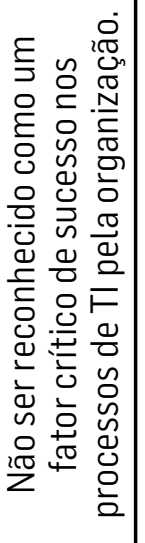 & 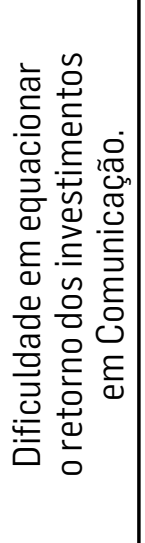 & 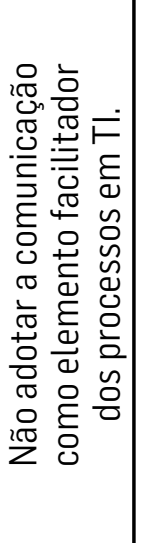 & 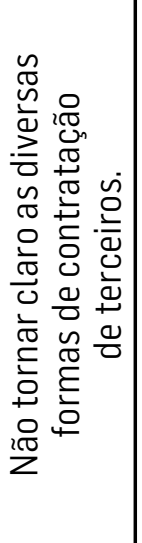 & 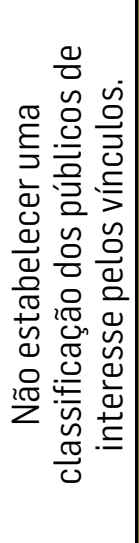 & \multirow[t]{2}{*}{ 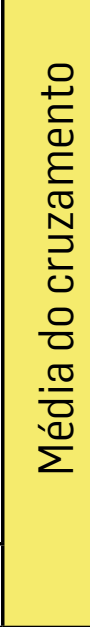 } & 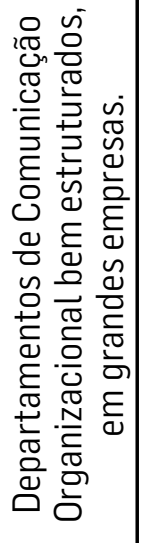 & 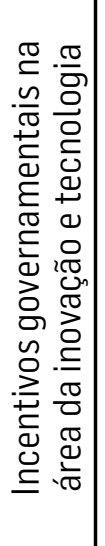 & 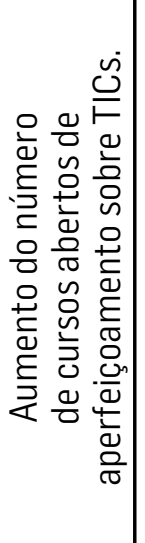 & 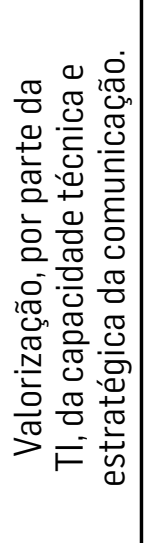 & 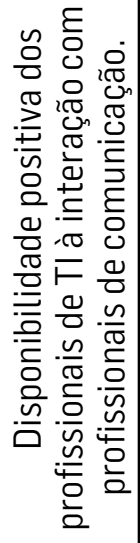 & \\
\hline & & & $\stackrel{\stackrel{2}{ }}{\square}$ & $\stackrel{\circ}{\sim}$ & $\stackrel{\stackrel{D}{N}}{\sim}$ & 8 & $\stackrel{\stackrel{2}{ }}{\square}$ & & $\simeq$ & $a$ & 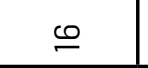 & 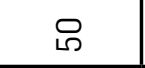 & 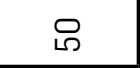 & \\
\hline \multirow{10}{*}{ 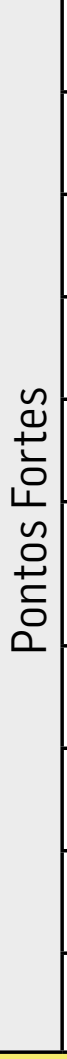 } & $\begin{array}{l}\text { Formação contempla habilidades } \\
\text { técnicas e gerenciais. }\end{array}$ & 6 & 65,5 & 40,5 & 65,5 & 33 & 65,5 & 54 & 9 & 15 & 11 & 28 & 28 & 18,2 \\
\hline & $\begin{array}{l}\text { Formação contempla habilidades } \\
\text { técnicas e gerenciais. }\end{array}$ & 3 & 64 & 39 & 64 & 31,5 & 64 & 52,5 & 7,5 & 6 & 9,5 & 26,5 & 26,5 & 15,2 \\
\hline & $\begin{array}{l}\text { Mais de } 50 \% \text { dos profissionais buscam } \\
\text { capacitação após a graduação. }\end{array}$ & 9 & 67 & 42 & 67 & 34,5 & 67 & 55,5 & 10,5 & 9 & 12,5 & 29,5 & 29,5 & 18,2 \\
\hline & $\begin{array}{l}\text { Experiências diversificadas } \\
\text { de interação com TI. }\end{array}$ & 32 & 78,5 & 53,5 & 78,5 & 46 & 78,5 & 67 & 22 & 20,5 & 24 & 41 & 41 & 29,7 \\
\hline & $\begin{array}{l}\text { Proximidade com as diversas } \\
\text { áreas organizacionais }\end{array}$ & 16 & 70,5 & 45,5 & 70,5 & 38 & 70,5 & 59 & 14 & 12,5 & 16 & 33 & 33 & 21,7 \\
\hline & $\begin{array}{l}\text { Principal foco das ações de } \\
\text { comunicação pautado no alinhamento } \\
\text { dos princípios organizacionais. }\end{array}$ & 12 & 68,5 & 43,5 & 68,5 & 36 & 68,5 & 57 & 12 & 10,5 & 14 & 31 & 31 & 19,7 \\
\hline & $\begin{array}{l}\text { Percepção da dificuldade de } \\
\text { interação da TI com os usuários. }\end{array}$ & 36 & 80,5 & 55,5 & 80,5 & 48 & 80,5 & 69 & 24 & 22,5 & 26 & 43 & 43 & 31,7 \\
\hline & $\begin{array}{c}\text { Percepção das dificuldades de expressão } \\
\text { e linguagem dos profissionais de TI }\end{array}$ & 36 & 80,5 & 55,5 & 80,5 & 48 & 80,5 & 69 & 24 & 22,5 & 26 & 43 & 43 & 31,7 \\
\hline & $\begin{array}{c}\text { Percepção da eficiência da comunicação } \\
\text { nas interações com a TI }\end{array}$ & 36 & 80,5 & 55,5 & 80,5 & 48 & 80,5 & 69 & 24 & 22,5 & 26 & 43 & 43 & 86,8 \\
\hline & $\begin{array}{l}\text { Demonstra disponibilidade para } \\
\text { compreender as necessidades de TI. }\end{array}$ & 60 & 92,5 & 67,5 & 92,5 & 60 & 92,5 & 81 & 36 & 34,5 & 38 & 55 & 55 & 43,7 \\
\hline \multicolumn{3}{|c|}{ Média do cruzamento } & 74,8 & 49,8 & 74,8 & 42,3 & 74,8 & & 18,3 & 17,6 & 20,3 & 37,3 & 37,3 & \\
\hline \multirow{8}{*}{ 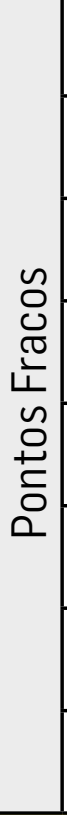 } & $\begin{array}{l}\text { Dificuldade em reconhecer o } \\
\text { potencial da área de TI. }\end{array}$ & 75 & 70,3 & 75 & 100 & 67,5 & 100 & 68,8 & 43,5 & 42 & 45,5 & 62,5 & 62,5 & 51,2 \\
\hline & $\begin{array}{c}\text { Baixo conhecimento sobre a dinâmica } \\
\text { e as especificidades da área de } \mathrm{TI}\end{array}$ & 48 & 86,5 & 61,5 & 86,5 & 54 & 86,5 & 62,5 & 30 & 28,5 & 32 & 49 & 49 & 37,7 \\
\hline & $\begin{array}{l}\text { Não integra o nível decisório } \\
\text { em muitas organizações. }\end{array}$ & 125 & 125 & 100 & 125 & 92,5 & 125 & 94,6 & 68,5 & 67 & 70,5 & 87,5 & 87,5 & 76,2 \\
\hline & $\begin{array}{l}\text { Confusão sobre o papel da } \\
\text { TI nas organizações. }\end{array}$ & 100 & 113 & 87,5 & 113 & 80 & 113 & 84,2 & 56 & 54,5 & 58 & 75 & 75 & 63,7 \\
\hline & $\begin{array}{l}\text { Não reconhece a interação como potencial } \\
\text { de diferencial competitivo e inovação. }\end{array}$ & 125 & 125 & 100 & 125 & 92,5 & 125 & 94,6 & 68,5 & 67 & 70,5 & 87,5 & 87,5 & 76,2 \\
\hline & $\begin{array}{l}\text { Percepção equivocada sobre os vínculos } \\
\text { dos profissionais de TI com a organização. }\end{array}$ & 80 & 103 & 77,5 & 103 & 70 & 103 & 75,8 & 46 & 44,5 & 48 & 65 & 65 & 53,7 \\
\hline & $\begin{array}{l}\text { Baixa percepção sobre a eficácia das ações } \\
\text { de comunicação na interação com TI. }\end{array}$ & 80 & 103 & 77,5 & 103 & 70 & 103 & 75,8 & 46 & 44,5 & 48 & 65 & 65 & 53,7 \\
\hline & $\begin{array}{l}\text { Não desenvolve política de comunicação } \\
\text { interna específica para a área de TI. }\end{array}$ & 125 & 125 & 100 & 125 & 92,5 & 125 & 94,6 & 68,5 & 67 & 70,5 & 87,5 & 87,5 & 76,2 \\
\hline \multicolumn{3}{|c|}{ Média do cruzamento } & 94,4 & 75,4 & 97,7 & 68,8 & 97,7 & & 47,4 & 46,1 & 49,2 & 64,3 & 64,3 & \\
\hline
\end{tabular}

Fonte: Velloso, 2014. 
No quadrante 1 (verde), destacam-se três aspectos que ameaçam a organização e afetam sua manutenção. Na relação com os pontos fortes da comunicação, encontra-se sustentação na disponibilidade dos profissionais de comunicação em "compreender as necessidades da TI". Esse aspecto deve ser explorado a fim de amenizar os impactos das ameaças.

No quadrante 2 (lilás), o máximo proveito é a valorização, por parte da TI, da "capacidade técnica e estratégica da comunicação" e a "disponibilidade positiva dos profissionais de TI à interação com profissionais de comunicação". Mais uma vez o ponto forte favorece a interface pela "disponibilidade que a comunicação demonstra para compreender as necessidades de Tl". Atesta-se que a prioridade na interface TI e comunicação é favorável para as áreas devido à disposição dos profissionais. Por outro lado, para a organização a viabilidade dos pontos destacados nas análises da realidade de TI, bem como da comunicação, é atendida em um cenário favorável e positivo, o que a destaca como um ponto representativo das "expectativas compartilhadas" entre as áreas.

Dentre os quesitos que se relacionam no cruzamento dos pontos fracos com ameaças e oportunidades, respectivamente quadrantes 3 (azul) e 4 (laranja), verifica-se que o primeiro demonstra uma situação mais crítica. Sendo assim, ao indicar nove intersecções que comprometem a sobrevivência da organização, verifica-se que as ameaças apontadas podem interferir negativamente na relação com os pontos fracos identificados na comunicação.

Portanto, cabe esclarecer que os três itens que ameaçam a organização no cenário de TI referentes à comunicação são potencializados na correspondência com os pontos fracos da comunicação referentes à TI. Isso demonstra o resultado de um distanciamento que a própria estrutura organizacional impõe a seus profissionais e às áreas de TI e de comunicação.

Percebe-se que a falta de interação mais efetiva nas organizações, entre a TI e a comunicação, é provocada pela segmentação organizacional que se faz entre elas. Pode-se deduzir que a visão tecnicista que a organização tem de ambas impede uma interação mais estratégica e, consequentemente, mais inovadora. Nesse sentido, o conjunto de ameaças potencializa 0 resultado negativo da intersecção, o que afeta a sobrevivência da organização.

\section{CONSIDERAÇÕES FINAIS}

Por meio da pesquisa com os profissionais de TI, foi possível identificar o sentimento positivo que eles têm quanto à contribuição do profissional de comunicação em seus processos. Isso porque reconhecem as dificuldades comunicativas e de relacionamento da área de TI e sua gravidade para a organização. Cabe ressaltar que, mesmo com a falta de conhecimento sobre a atuação de comunicação, os profissionais de TI demonstraram expectativas positivas sobre a interface, em nível estratégico e técnico.

Ao orientar a estruturação metodológica de sua pesquisa pelas problemáticas da interculturalidade no cenário de internacionalização das organizações, a tese de Velloso (2014) destaca a importância do "núcleo de conhecimento" e das "expectativas compartilhadas" para elaboração de uma proposta baseada na "cultura participativa".

Ao demonstrar a positividade da interface entre profissionais de comunicação e TI para a organização, a pesquisa permitiu a proposição de uma comunicação sistêmica em TI pautada por uma evolução participativa agrupada em quatro blocos: 1. Sensibilização e esclarecimento; 2. Envolvimento e participação; 3. Colaboração; e 4. Sustentação dos relacionamentos. 
No cenário de comunicação e no cenário de TI, as expectativas compartilhadas evidenciaram a necessidade do posicionamento da comunicação no nível de governança organizacional e, dessa forma, faz-se necessário um modelo processual estratégico de duas mãos da comunicação no conjunto organizacional de governança e gestão.

Portanto, a interculturalidade, em cenários complexos como o das organizações, propicia a construção de uma visão crítica sobre seus conflitos e suas potencialidades. Associadas às técnicas de observação, coleta e análises, com um suporte teórico alinhado, podem oferecer resultados estruturados e consistentes para aaplicação de políticas eestratégias de comunicação nas organizações.

\section{REFERÊNCIAS}

BERNARD, H. Russell. Research methods in anthropology: qualitative and quantitative approaches. American Journal of Evaluation, n. 17, p. 91-92,1996.

CASTELLS, Manuel. A era da informação: economia, sociedade e cultura. Vol. 1: A sociedade em rede. Trad. de Roneide Venancio Majer e colaboração de Klauss Brandini Gerhardt. 11. ed. - atualizada. São Paulo: Paz e Terra, 2008.

DOZIER David M.; GRUNIG, Larissa; GRUNIG, James. Manager's guide to excellence in public relations and communication management. Mahwah, NJ: Lawrence Erlbaum, 1995.

DUARTE, Jorge; BARROS, Antonio (Org.). Métodos e técnicas de pesquisa em comunicação. São Paulo: Atlas, 2010.

FERRARI, Maria Aparecida. Gestão da comunicação intercultural nas organizações brasileiras em tempos de globalização. Comunicologia - Revista de Comunicação e Epistemologia da Universidade Católica de Brasília, v. 5, n. 1, 2012.

GARCÍA-CANCLINI, Néstor. Culturas híbridas: estratégias para entrar e sair da modernidade. 4. ed. São Paulo: Editora da Universidade de São Paulo, 2003.

GIL, Antonio Carlos. Como elaborar projetos de pesquisa. 4. ed. São Paulo: Atlas, 2002.

GRUNIG, James E. (Org.). Excellence in public relations and communication management. Hillsdale, NJ: Lawrence Erlbaum Associates, 1992.

. Uma teoria geral das relações públicas: quadro teórico para o exercício da profissão. In: GRUNIG, James E., FERRARI, Maria Aparecida; FRANÇA, Fábio. Relações públicas: teoria contexto e relacionamentos. São Paulo: Difusão, 2009.

IANNI, Octavio. A dialética da globalização. In: Teorias da globalização. Rio de Janeiro: Civilização Brasileira, 2004. . A sociedade global. Rio de Janeiro: Civilização Brasileira, 2005.

KEPNER, Charles H.; TREGOE, Benjamin B. O administrador racional: uma abordagem sistemática à solução de problemas e tomadas de decisão. São Paulo: Atlas, 1981. 
KUNSCH, Margarida M. Krohling. Relações públicas e excelência em comunicação. Disponível em: <http://www.portal-rp. com.br/bibliotecavirtual/relacoespublicas/ teoriaseconceitos/0081.htm>. Acessado em: 05 mar. 2010.

LAKATOS, Eva Maria; MARCONI, Marina de Andrade. Metodologia do trabalho científico. 6. ed. São Paulo: Atlas, 2001.

LAURINDO, Fernando J. B. Tecnologia da informação: planejamento e gestão de estratégias. São Paulo: Atlas, 2008.

MEIRELES, Manuel. Ferramentas administrativas para identificar, observar e analisar problemas: organizações com foco no cliente. São Paulo: Arte \& Ciência, 2001.

OLIVEIRA, Djalma de Pinto Rebouças de. Planejamento estratégico: conceitos, metodologias e práticas. 18. Ed. - rev. e ampl. São Paulo: Atlas, 2002.

REBEIL CORELLA, Maria Antonieta. Subsistemas organizacionais e comunicação. In: KUNSCH, Margarida M. Krohling (Org.). Relações públicas e comunicação organizacional: campos acadêmicos e aplicados de múltiplas perspectivas. São Caetano do Sul, SP: Difusão Editora, 2009. p. 95-109.

SAMARA, Betriz Santos; BARROS, José Carlos. Pesquisa de marketing: conceitos e metodologias. 4. ed. São Paulo: Pearson Prentice Hall, 2007.

VELLOSO, Viviane Fushimi. A interação de tecnologias da informação e comunicação no alinhamento das melhores práticas empresariais. 2014. 225 f. Tese (Doutorado em Ciências da Comunicação) - Escola de Comunicações e Artes, Universidade de São Paulo, São Paulo, 2014.

YANAZE, Mitsuru Higuchi. Gestão de marketing e comunicação: avanços e aplicações. 2. ed. São Paulo; Saraiva, 2011.

Artigo recebido em 20.08.2014 e aprovado em 17.11.2014. 